\title{
The degree of local inflammatory response after colonic resection depends on the surgical approach: an observational study in 61 patients
}

Torben Glatz , Ann-Kathrin Lederer, Birte Kulemann, Gabriel Seifert, Philipp Anton Holzner, Ulrich Theodor Hopt, Jens Hoeppner and Goran Marjanovic

\begin{abstract}
Background: Clinical data indicate that laparoscopic surgery reduces postoperative inflammatory response and benefits patient recovery. Little is known about the mechanisms involved in reduced systemic and local inflammation and the contribution of reduced trauma to the abdominal wall and the parietal peritoneum.

Methods: Included were 61 patients, who underwent elective colorectal resection without intraabdominal complications; 17 received a completely laparoscopic, 13 a laparoscopically- assisted procedure and 31 open surgery. Local inflammatory response was quantified by measurement of intraperitoneal leukocytes and IL-6 levels during the first 4 days after surgery.

Results: There was no statistical difference between the groups in systemic inflammatory parameters and intraperitoneal leukocytes. Intraperitoneal interleukin- 6 was significantly lower in the laparoscopic group than in the laparoscopically-assisted and open group on postoperative day 1 ( 26.16 versus 43.25 versus $40.83 \mathrm{ng} / \mathrm{ml} ; p=0.001$ ). No difference between the groups was recorded on POD 2-4. Intraperitoneal interleukin-6 showed a correlation with duration of hospital stay on POD $1(0.233, p=0.036)$, but not on POD 2-4.

Patients who developed a surgical wound infection showed higher levels of intraperitoneal interleukin- 6 on postoperative day 2-4 (POD 2: 42.56 versus $30.02 \mathrm{ng} / \mathrm{ml}, p=0.03$ ), POD 3: 36.52 versus $23.62 \mathrm{ng} / \mathrm{ml}, p=0.06$ and POD 4: 34.43 versus $19.99 \mathrm{ng} / \mathrm{ml}, p=0.046)$. Extraabdominal infections had no impact.

Conclusion: The analysis shows an attenuated intraperitoneal inflammatory response on POD 1 in completely laparoscopically-operated patients, associated with a quicker recovery. This effect cannot be observed in patients, who underwent a laparoscopically-assisted or open procedure. Factors inflicting additional trauma to the abdominal wall and parietal peritoneum promote the intraperitoneal inflammation process.
\end{abstract}

Keywords: Laparoscopic surgery, Laparoscopically-assisted surgery, Peritoneal inflammation, Cytokines, Wound healing

\section{Background}

Major abdominal surgery and laparotomy causes a release of local and systemic cytokines, inducing a systemic inflammatory response syndrome [1-3]. Local peritoneal inflammation is thought to play a role in patient recovery and in development of perioperative complications [4-7].

*Correspondence: Torben.Glatz@uniklinik-freiburg.de

Department of General and Visceral Surgery, Albert Ludwigs University of Freiburg, Freiburg im Breisgau, Germany
Laparoscopic surgery has been shown to attenuate both local and systemic inflammatory response [8-13].

Today, minimally-invasive bowel resection has been established as a standard procedure in most hospitals. Retrospective analyses indicate a beneficial effect of laparoscopically- performed surgery on patient recovery and even on the occurrence of serious complications like anastomotic leak and on patient survival [14-17].

In an attempt to quantify the systemic and local impact of laparoscopic surgery on the inflammatory response, systemic and intraperitoneal (ip) interleukin-6 
(IL-6) has been established as a sensitive marker of inflammation on postoperative day 1 after surgery. Low ip levels of IL-6 are associated with faster recovery and earlier hospital discharge $[13,18]$. Several studies show lower levels of systemic IL- 6 on day 1 after laparoscopic surgery [12], while only one study exists illustrating the effect of laparoscopic surgery on ip IL-6 [13]. All others studies have failed to establish a difference in intraperitoneal cytokines between laparoscopic and conventional surgery [19-21]. Most of these studies did not include completely laparoscopic operations, but only laparoscopically-assisted procedures with laparotomy after colonic mobilization, which might induce an increased local inflammatory response compared to a completely laparoscopic procedure. The aim of this study is to determine whether postoperative intraperitoneal inflammation depends on the surgical technique and the trauma inflicted on the abdominal wall by quantifying local inflammatory response via ip IL-6 levels during the first days after colorectal surgery in patients undergoing a completely laparoscopic, a laparoscopically-assisted or an open procedure.

\section{Methods}

\section{Patients and operative procedure}

The observational study includes 61 consecutively operated patients, who underwent elective colorectal resection from January to December 2013 at our institution. Only patients without major intraabdominal complications were included. Informed consent was obtained from all patients before operation and inclusion in the study. Institutional Review Board approval was granted for the sample collection and evaluation of patient demographics (EK-F: 345/12) by the Medical Ethics Committee of the University of Freiburg, the study was carried out according to the Helsinki Declaration. Data were collected with regard to patient demographics, details of disease, operative procedure and extraabdominal complications. Complications were defined by standardized definitions and graded according to the Clavien-Dindo classification [22, 23].

Procedures included in the study were left-sided colon resections (sigmoid resection $[n=21]$, left hemicolectomy $[n=19])$ and anterior rectum resection $(n=21)$. All operations were performed by or under supervision of experienced colorectal surgeons. The surgical approach (laparoscopic, laparoscopically-assisted or open) was chosen by the operating surgeon. Patients were not randomized to the groups. The patients were retrospectively assigned to the group according to the operation technique. Four operations were converted from laparoscopic to open and were assigned to the open group. The laparoscopically-assisted procedure was defined as a laparoscopic mobilization of the colon and fashioning of the anastomosis through a small lower medial laparotomy $(6-12 \mathrm{~cm})$, while the completely laparoscopic operation was characterized by laparoscopic fashioning of the anastomosis and removal of the resected bowel through a suprapubic mini-laparotomy $(3-5 \mathrm{~cm})$ after complete laparoscopic mobilization. Our definitions are concordant with the literature [24, 25].

Postoperatively, patients received standardized pain medication (metamizole, oxycodone and piritramide). Anti-inflammatory drugs were omitted whenever possible.

\section{Sample collection and storage}

Patients included in the study had a $10 \mathrm{~mm}$ Intersil ${ }^{\circ}$ Silicone X-Ray Capillary Drain (Mikrotek ${ }^{\circ}$ medical, Mosta, MT) inserted into the Douglas cavity during surgery. The intraperitoneal fluid was collected in a collecting bag (Urine bag, Asis Bonz ${ }^{\circ}$, Herrenberg, $\mathrm{DE})$. The drain was removed on postoperative day 4 after collection of samples.

Drainage clearance was performed daily at $6 \mathrm{am}$. Two to four hours later, fresh drainage fluid was collected on POD 1-4 and venous blood samples were taken on POD 1, 3, and 5. All samples were sent immediately to the Freiburg university hospital laboratory for further analyses.

\section{Parameter analyses}

Analyzed were serum leukocytes on POD 1, 3 and 5 and serum c-reactive protein (CRP) on POD 3 and 5 as part of the routine follow-up. Intraperitoneal leukocytes and IL-6 were measured on POD 1-4. In 6 patients, measurement of intraperitoneal leukocytes was not possible due to lack of material. On POD 4, the drain had already been removed in 9 patients, thus no material was taken for analyses. Parameter analyses were performed with the modular analyzer Cobas 8000 (Roche ${ }^{\circ}$ Diagnostics, Rotkreuz, Risch, $\mathrm{CH}$ ) for IL-6 and CRP and the XN$9000^{\circ}$ (Sysmex ${ }^{\circ}$ Corporation, Kobe, JP) for leukocytes.

\section{Statistical analysis}

Results are expressed as mean $\pm \mathrm{SD}$ and medians with range, as appropriate. The primary outcome parameter was ip IL-6, the secondary outcome measures were ip leukocytes, systemic leukocytes, CRP and patient demographics. Differences between categorical variables were evaluated by Fisher's exact test. Differences between continuous variables were measured using the KruskalWallis test or Mann-Whitney-U-test, as appropriate. SPSS for Windows" was used for statistical analysis (SPSS, Chicago, IL, USA). A Spearman's correlation coefficient was employed to express the correlations. $P<0.05$ was considered significant. 


\section{Results}

Patients

Among the 61 patients, 17 were operated completely laparoscopically, 13 laparoscopically- assisted with additional laparotomy and 31 underwent open surgery. Twenty-six patients were male and 35 female, the mean age was 56.7 years $( \pm 16.4)$. Thirty-one patients were operated with an underlying benign disease, 30 had a malignant disease. Mean operating time was 193 min (Table 1). There were no significant differences in sex $(p=0.10)$, age $(p=0.29)$ or performed procedure $(p=0.24)$ between the groups, though the majority of patients in the laparoscopic group were women (76\%). There were more malignancies in the open and laparascopically-assisted groups than in the laparoscopic group $(p=0.04)$.

\section{Systemic inflammatory parameters and intraperitoneal leukocytes}

Systemic leukocytes were mildly elevated on POD 1 (11.71 thsd $/ \mu \mathrm{l}$ ) and returned to normal values on POD 3 and 5 (Table 2). There was no statistical difference among the three groups. Serum CRP-levels tended to be higher in the open compared to the completely laparoscopicallyoperated group on POD 3 (119 versus $82 \mathrm{mg} / \mathrm{l}$ ) without being significant $(p=0.22)$. There was no difference among the groups on POD 5 (Table 2).

Intraperitoneal leukocytes were very heterogeneously distributed with high standard deviation and no significant difference between the groups (Table 2).

Table 1 Patient demographics and treatment specifications

\begin{tabular}{ll}
\hline & Total $(n=61)$ \\
\hline Age (years, mean \pm SD) & $56.7 \pm 16.4$ \\
$\quad$ Male ( $n)$ & \\
$\quad$ Female ( $n)$ & $43 \%(26)$ \\
Disease ( $n$ ) & $57 \%(35)$ \\
$\quad$ Benign & \\
$\quad$ Malignant & $51 \%(31)$ \\
Operation ( $n)$ & $49 \%(30)$ \\
$\quad$ Left-sided colon resection & \\
$\quad$ Anterior rectum resection & $66 \%(40)$ \\
Operating time (min, mean \pm SD) & $34 \%(21)$ \\
Extrabdominal complications (grade) & $193 \pm 72$ \\
$\quad$ Wound infection (II-IIla) & $26 \%(16)^{\mathrm{a}}$ \\
$\quad$ Urinary-tract-infection (II) & $14 \%(8)$ \\
$\quad$ Pneumonia (II) & $10 \%(6)$ \\
Other (II-IIIa) & $4 \%(2)$ \\
Hospital stay [days, median (range)] & $4 \%(2)$ \\
\hline
\end{tabular}

${ }^{\mathrm{a}} 2$ patients had more than one complication

\section{Patient demographics, surgical technique and intraperitoneal IL-6}

Mean total values of ip IL-6 were very high on POD 1 (37.26 ng/ml) and were halved by POD 4 (Table 2). Levels were significantly lower in the completely laparoscopically-operated group on POD 1 compared to the laparoscopically-assisted and the open group (26.16 versus 43.25 versus $40.83 \mathrm{ng} / \mathrm{ml} ; p=0.004$; Fig. 1).

Age, type of operation (left-sided colon resection versus anterior rectum resection) and type of disease (malignant versus benign) had no impact on the concentration of ip IL-6. Female patients showed consistently lower levels than male patients on all postoperative days (POD 1: 42.18 versus $33.60 \mathrm{ng} / \mathrm{ml}, p=0.007$; POD 2: 37.11 versus $27.62 \mathrm{ng} / \mathrm{ml}, p=0.03$; POD $3: 32.28$ versus $20.13 \mathrm{ng} / \mathrm{ml}, p=0.004$; POD 4: 27.07 versus $17.52 \mathrm{ng} / \mathrm{ml}$, $p=0.04)$.

Separate analysis of the female group $(n=34)$ showed consistent results with the overall collective: Female patients who underwent a completely laparoscopic procedure had lower levels of ip IL-6 than those after laparoscopically-assisted or the open procedure on POD 1 (female patients: 23.92 versus 41.29 versus $38.74 \mathrm{ng} / \mathrm{ml}, p=0.03)$.

\section{Perioperative complications and intraperitoneal IL- 6}

The study only includes patients without intraabdominal complications (anastomotic leak, abscess). There were no mortalities. Twenty-six percent of the patients had a perioperative complication (the most common being wound infection and urinary tract infection), one patient had a deep vein thrombosis and was treated with i.v. heparin, another suffered from NSTEMI and underwent percutaneous coronary intervention. The number of complications did not differ among the groups $(p=0.40)$.

Patients who developed wound infection showed a higher IL-6 concentration on POD 2 (42.56 versus $30.02 \mathrm{ng} / \mathrm{ml}, p=0.03$ ), POD 3 (36.52 versus $23.62 \mathrm{ng} / \mathrm{ml}$, $p=0.06)$ and POD 4 (34.43 versus $19.99 \mathrm{ng} / \mathrm{ml}, p=0,046)$, while pulmonary and urinary tract infections had no impact on ip IL-6-levels (Fig. 2).

\section{Hospital stay and Intraperitoneal IL-6}

Hospital stay was significantly lower in the laparoscopic and the laparoscopically-assisted than in the open group $(p=0.01)$. There was no difference between the two laparoscopic groups $(p=0.77$, Table 1$)$. To analyze a possible correlation between ip IL-6 levels and the duration of hospital stay, we calculated a Spearman's correlation coefficient for these variables. A positive correlation was found for ip IL-6 concentration on POD $1(0.233 ; p=0.04)$, but not on POD $2(0.058, p=0.66)$, POD $3(0.090, p=0.49$ or POD $4(-0.062,0.66)$. 
Table 2 Systemic and local inflammatory parameters after open and laparoscopic surgery

\begin{tabular}{|c|c|c|c|c|c|c|}
\hline & POD & Total $(n=61)$ & Laparoscopic $(n=17)$ & Lap.-assisted $(n=13)$ & Open $(n=31)$ & $P^{a}$ \\
\hline \multirow[t]{2}{*}{ Leukocytes (serum) } & 1 & $11.71 \pm 4.40$ & $10.91 \pm 4.35$ & $10.75 \pm 3.19$ & $12.56 \pm 4.81$ & 0.39 \\
\hline & 3 & $8.41 \pm 3.31$ & $8.07 \pm 4.13$ & $8.40 \pm 3.21$ & $8.61 \pm 2.94$ & 0.70 \\
\hline Thsd/pl & 5 & $7.50 \pm 2.93$ & $7.76 \pm 4.11$ & $7.52 \pm 2.42$ & $7.35 \pm 2.40$ & 0.99 \\
\hline CRP & 3 & $104 \pm 67$ & $82 \pm 65$ & $100 \pm 58$ & $119 \pm 69$ & 0.22 \\
\hline $\mathrm{mg} / \mathrm{l}$ & 5 & $69 \pm 57$ & $75 \pm 70$ & $59 \pm 48$ & $70 \pm 53$ & 0.55 \\
\hline Leukocytes ip & 1 & $10.67 \pm 12.93$ & $11.16 \pm 14.48$ & $9.23 \pm 6.18$ & $10.89 \pm 14.02$ & 0.83 \\
\hline \multirow[t]{3}{*}{ Thsd/pl } & 2 & $8.39 \pm 13.25$ & $11.52 \pm 18.02$ & $3.02 \pm 2.27$ & $8.41 \pm 11.84$ & 0.38 \\
\hline & 3 & $9.73 \pm 20.34$ & $18.69 \pm 32.64$ & $6.17 \pm 11.25$ & $5.57 \pm 8.99$ & 0.92 \\
\hline & 4 & $6.01 \pm 13.93$ & $14.43 \pm 25.89$ & $3.5 \pm 6.24$ & $3.31 \pm 5.28$ & 0.41 \\
\hline IL-6 ip & 1 & $37.26 \pm 15.30$ & $26.16 \pm 17.53$ & $43.25 \pm 10.47$ & $40.83 \pm 12.74$ & 0.004 \\
\hline \multirow[t]{3}{*}{$\mathrm{ng} / \mathrm{ml}$} & 2 & $31.66 \pm 16.59$ & $27.56 \pm 17.43$ & $35.34 \pm 14.51$ & $32.37 \pm 16.97$ & 0.30 \\
\hline & 3 & $25.31 \pm 16.78$ & $22.38 \pm 16.44$ & $29.26 \pm 18.17$ & $25.25 \pm 16.58$ & 0.59 \\
\hline & 4 & $21.93 \pm 16.91$ & $21.50 \pm 20.18$ & $21.50 \pm 16.91$ & $22.31 \pm 16.19$ & 0.93 \\
\hline
\end{tabular}

Results are presented as mean \pm SD in $\mathrm{ng} / \mathrm{ml}$. Significant results are bold ${ }^{\mathrm{a}}$ Kruskal-Wallis test

\section{Discussion}

Quantification of local and systemic inflammatory response has shown a decreased inflammatory response after laparoscopic compared to open surgery [8-13]. Intraperitoneal IL-6 is a promising parameter of intraperitoneal inflammatory response after different kinds of abdominal surgery. Low intraperitoneal levels of IL-6 during the first $24 \mathrm{~h}$ after colonic surgery correlate with faster recovery and earlier hospital discharge [13] while high levels seem to favour the development of postoperative fatigue [18].

IL-6 has primarily been studied during the initial $24 \mathrm{~h}$ after surgery. We present the first study analyzing the physiological course of ip IL-6 levels over 4 days after colonic surgery.

In this study, patients were not randomized to the groups and not matched for type of operation and disease, sex and age to ensure best possible care for every patient. While type of disease had no impact on ip IL-6 levels, surprisingly female patients had consistently lower levels of ip IL-6, but separate analysis of the female group confirmed our findings: Lower levels of ip IL-6 after completely laparoscopic surgery on POD 1. Deviation in cytokine response under different circumstances among men and woman has been reported before in different medical fields [26-28], but reasons remain unexplained.

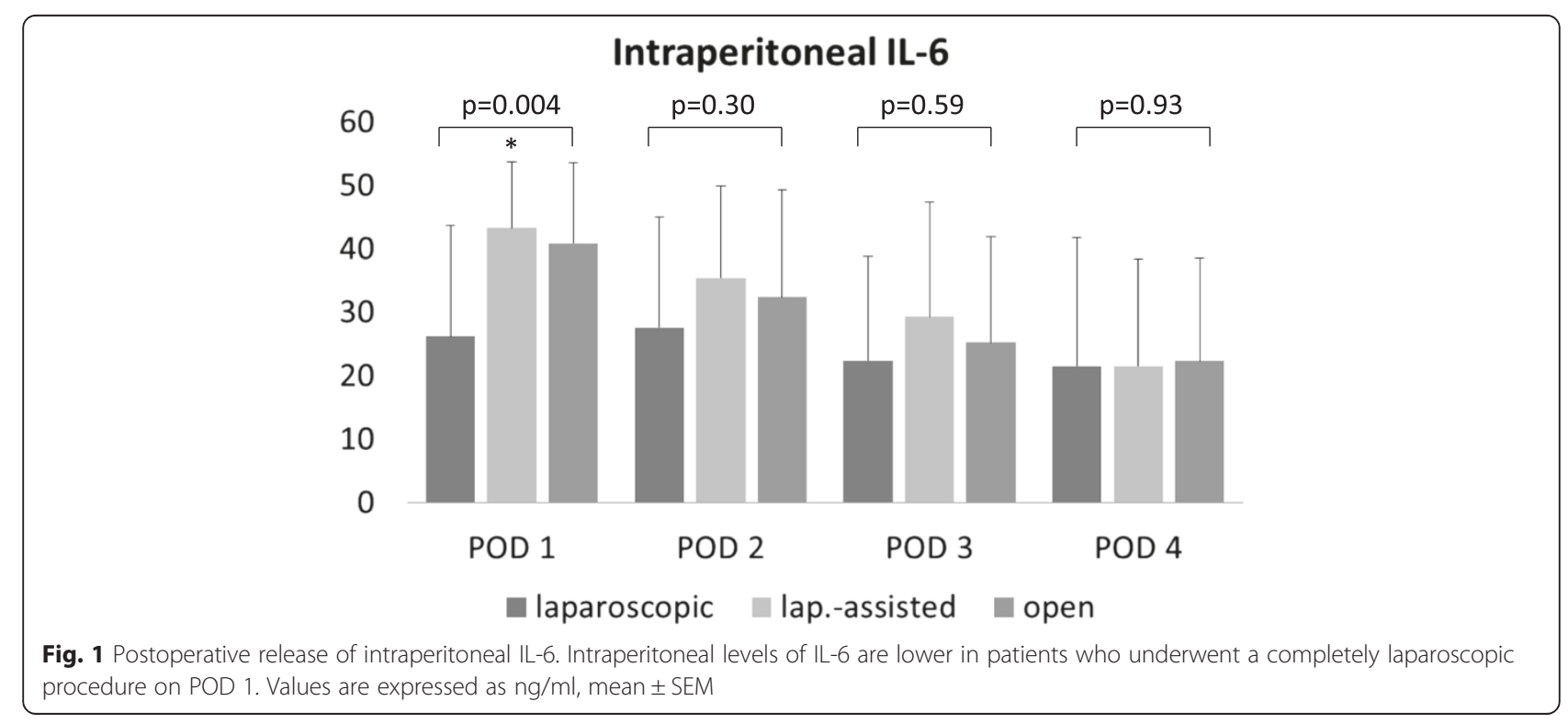




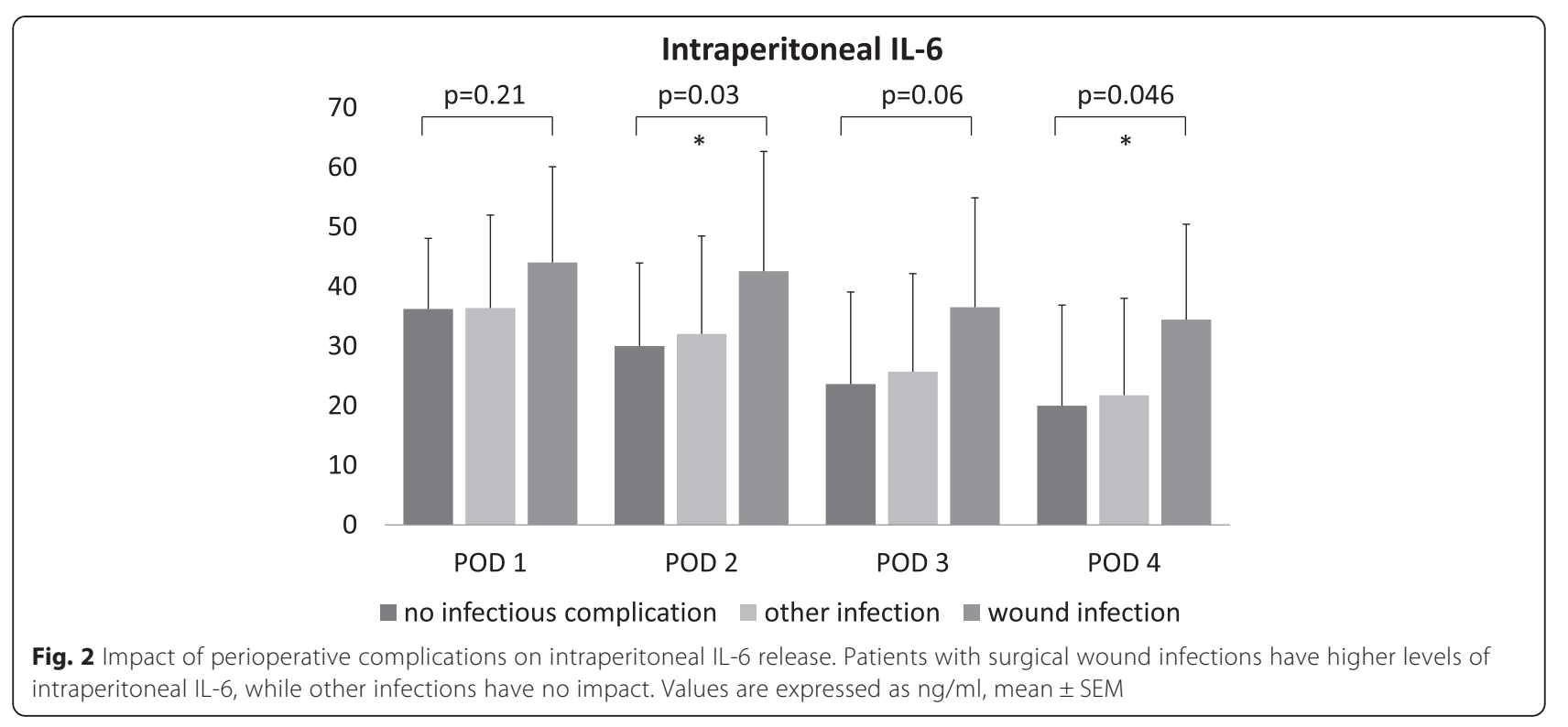

Decreased levels of ip IL-6 on POD 1 after laparoscopic surgery were shown for the first time in 2012 [13]. In addition, we were able to show that this effect does not apply to patients who underwent a laparoscopicallyassisted procedure. A few earlier analyses studied the effect of laparoscopic surgery on cytokine release. These studies were able to show a diminished systemic release of IL-6 after laparoscopic surgery, but failed to show a difference in ip IL-6 levels [19-21]. Study design was compromised by a small number of patients and also included mainly patients who underwent a laparoscopically-assisted procedure and not a completely laparoscopic operation. Our data indicate that the local inflammatory response after laparoscopically-assisted surgery compares to that following open surgery. Thus, additional laparotomy and therefore increased trauma to the abdominal wall and the parietal peritoneum seems to promote intraperitoneal inflammation.

The factors actually responsible for the clinicallyobserved beneficial effects of laparoscopic surgery are not well known $[29,30]$. Some studies show that the effects of the pneumoperitoneum on peritoneum and wound healing compare to those of a laparotomy [31-33]. In our setting, however, local inflammation depended partly on the amount of surgical trauma inflicted to the abdominal wall. Until today, many surgeons have opted for a laparoscopically-assisted procedure because it has a flat learning curve, can be performed in a shorter period of time and offers a safe and easy way to fashion the anastomosis [24, 25]. Our data indicate, though, that the beneficial effects observed and proven for laparoscopic surgery regarding attenuated inflammatory response might not apply to laparoscopically-assisted surgery.
We and others [13] were able to show a correlation between ip IL-6 levels on POD 1 and patient recovery, supporting our hypothesis. However, in this study the difference in hospital stay between the laparoscopic and laparoscopically-assisted groups was not significant and the clinical relevance of an additional / longer abdominal wall incision seems to be rather low in this setting. The impact and significance of ip IL-6 levels at later time points after surgery remains unknown. Our data show no correlation between IL- 6 levels and patient recovery on POD 2-4.

Intraperitoneal IL-6 has been proposed as a diagnostic tool for early detection of anastomotic leaks [34, 35]. In this study, patients who developed an anastomotic leak have higher levels of ip IL- 6 on POD 1, 3 and 5 than patients with an uneventful postoperative course [35]. Patients with intraabdominal complications were excluded from this analysis, but the data show that surgical wound infections without involvement of the intraabdominal cavity stimulate release of ip IL-6. Levels were higher on POD 2-4, an effect possibly mediated by affection of the parietal peritoneum. Due to incomplete healing of the abdominal fascia, the infection can easily involve the parietal peritoneum. Besides the direct involvement of the peritoneum, we suspect involvement of other cytokines mediating intraperitoneal inflammation after injury of the abdominal wall. Intraperitoneal IL-6 was not affected by extraabdominal infections like pneumonia or urinary tract infection and therefore seems to be more specific than systemic inflammatory parameters.

Additionally, this finding contributes to our impression that trauma and inflammation of the abdominal wall and parietal peritoneum has an impact on the intraabdominal inflammation process. However the mechanisms by which 
extraperitoneal stimuli might or might not effect intraperitoneal inflammation are not completely understood.

In our study, analyses of ip leukocytes revealed no differences between different operating techniques. The significance of postoperative intraperitoneal leukocytes as a diagnostic marker for intraperitoneal inflammation or perioperative complications remains unknown $[1,2]$.

\section{Conclusions}

We analyzed the physiological course of ip IL-6 over POD 1-4 in patients after colonic resection and were able to show an attenuated intraperitoneal inflammatory response on POD 1 only in completely laparoscopicallyoperated patients, while this effect could not be observed in patients who underwent a more traumatic laparoscopically-assisted or even open procedure. Thus, we conclude that the degree of intraperitoneal inflammation depends not only on the trauma inflicted on the bowel but also to a major part on the extent of trauma to the abdominal wall and parietal peritoneum. Even if the clinical significance of these data appears to be rather low, we provide further basic knowledge of the impact of laparoscopic techniques on the postoperative healing process which should be more precisely explored in future randomized trials.

\section{Competing interests}

The authors declare that they have no competing interests.

\section{Authors' contributions}

TG and GM were responsible for conception and design of the study and drafted the Manuscript. AL, BK, GS and PH were responsible for collection of clinical data and assisted with analyses and interpretation. $\mathrm{JH}$ and $\mathrm{UH}$ revised the article. All authors have approved the manuscript.

\section{Authors' information}

Not applicable.

\section{Acknowledgements}

All authors were funded by the Department of General Surgery, University Hospital Freiburg. The article processing charge was funded by the German Research Foundation (DFG) and the Albert Ludwigs University Freiburg in the funding program Open Access Publishing. The authors thank Jodok Fink for his contribution to revision of the manuscript and Olivia Sick for her contribution in acquiring the data.

Received: 24 April 2015 Accepted: 1 October 2015

Published online: 06 October 2015

\section{References}

1. Tsukada K, Katoh H, Shiojima M, Suzuki T, Takenoshita S, Nagamachi Y. Concentrations of cytokines in peritoneal fluid after abdominal surgery. Eur J Surg. 1993;159:475-9.

2. Badia JM, Whawell SA, Scott-Coombes DM, Abel PD, Williamson RC, Thompson JN. Peritoneal and systemic cytokine response to laparotomy. Br J Surg. 1996:83:347-8.

3. Riese J, Schoolmann S, Beyer A, Denzel C, Hohenberger W, Haupt W. Production of IL-6 and MCP-1 by the human peritoneum in vivo during major abdominal surgery. Shock. 2000;14:91-4.

4. Hegarty N, Dasgupta P. Immunological aspects of minimally invasive oncologic surgery. Curr Opin Urol. 2008;18:129-33.
5. Frasko R, Maruna P, Gurlich R, Trca S. Transcutaneous electrogastrography in patients with ileus. Relations to interleukin-1 beta, interleukin-6, procalcitonin and C-reactive protein. Eur Surg Res. 2008;41:197-202.

6. Holmdahl L, Kotseos K, Bergström M, Falk P, Ivarsson ML, Chegini N Overproduction of transforming growth factor-beta1 (TGF-beta1) is associated with adhesion formation and peritoneal fibrinolytic impairment. Surgery. 2001;129:626-32.

7. Coffey JC, Smith MJF, Wang JH, Bouchier-Hayes D, Cotter TG, Redmond HP. Cancer surgery: risks and opportunities. Bioessays. 2006;28:433-7.

8. Wang G, Jiang Z, Zhao K, Li G, Liu F, Pan H, et al. Immunologic response after laparoscopic colon cancer operation within an enhanced recovery program. J Gastrointest Surg. 2012;16:1379-88.

9. Veenhof AAFA, Vlug MS, van der Pas MHGM, Sietses C, van der Peet $\mathrm{DL}$, de Lange-de Klerk ESM, et al. Surgical stress response and postoperative immune function after laparoscopy or open surgery with fast track or standard perioperative care: a randomized trial. Ann Surg. 2012;255:216-21.

10. Luk JM, Tung PH, Wong K, Chan K, Law S, Wong J. Laparoscopic surgery induced interleukin-6 levels in serum and gut mucosa: implications of peritoneum integrity and gas factors. Surg Endosc. 2009;23:370-6.

11. Gracia M, Sisó C, Martínez-Zamora MÀ, Sarmiento L, Lozano F, Arias MT, et al. Immune and stress mediators in response to bilateral adnexectomy: comparison of single-port access and conventional laparoscopy in a porcine model. J Minim Invasive Gynecol. 2014;21:837-43.

12. Sammour T, Kahokehr A, Chan S, Booth RJ, Hill AG. The humoral response after laparoscopic versus open colorectal surgery: a meta-analysis. I Surg Res. 2010;164:28-37.

13. Sammour T, Kahokehr A, Zargar-Shoshtari K, Hill AG. A prospective casecontrol study of the local and systemic cytokine response after laparoscopic versus open colonic surgery. J Surg Res. 2012;173:278-85.

14. Li JC, Leung KL, Ng SS, Liu SY, Lee JF, Hon SS. Laparoscopic-assisted versus open resection of right-sided colonic cancer-a prospective randomized controlled trial. Int J Colorectal Dis. 2012;27:95-102.

15. Day AR, Smith RVP, Jourdan IC, Rockall TA. Survival following laparoscopic and open colorectal surgery. Surg Endosc. 2013;27:2415-21.

16. Luján JJ, Németh ZH, Barratt-Stopper PA, Bustami R, Koshenkov VP, Rolandelli RH. Factors influencing the outcome of intestinal anastomosis. Am Surg. 2011;77:1169-75.

17. Levack M, Berger D, Sylla P, Rattner D, Bordeianou L. Laparoscopy decreases anastomotic leak rate in sigmoid colectomy for diverticulitis. Arch Surg. 2011;146:207-10

18. Paddison JS, Booth RJ, Fuchs D, Hill AG. Peritoneal inflammation and fatigue experiences following colorectal surgery: a pilot study. Psychoneuroendocrinology. 2008;33:446-54.

19. Hewitt PM, Ip SM, Kwok SP, Somers SS, Li K, Leung KL, et al. Laparoscopicassisted vs. open surgery for colorectal cancer: comparative study of immune effects. Dis Colon Rectum. 1998;41:901-9.

20. Ozawa A, Konishi F, Nagai H, Okada M, Kanazawa K. Cytokine and hormonal responses in laparoscopic-assisted colectomy and conventional open colectomy. Surg Today. 2000;30:107-11.

21. Wu FPK, Sietses C, von Blomberg BME, van Leeuwen PAM, Meijer S, Cuesta MA. Systemic and peritoneal inflammatory response after laparoscopic or conventional colon resection in cancer patients: a prospective, randomized trial. Dis Colon Rectum. 2003;46:147-55.

22. Clavien PA, Barkun J, de Oliveira ML, Vauthey JN, Dindo D, Schulick RD, et al The Clavien-Dindo classification of surgical complications: five-year experience. Ann Surg. 2009;250:187-96.

23. Dindo D, Demartines N, Clavien P. Classification of surgical complications: a new proposal with evaluation in a cohort of 6336 patients and results of a survey. Ann Surg. 2004;240:205-13.

24. Bernstein MA, Dawson JW, Reissman P, Weiss EG, Nogueras JJ, Wexner SD. Is complete laparoscopic colectomy superior to laparoscopic assisted colectomy? Am Surg. 1996;62:507-11.

25. Magistro C, Di Lernia S, Ferrari G, Zullino A, Mazzola M, de Martini P, et al. Totally laparoscopic versus laparoscopic-assisted right colectomy for colon cancer: is there any advantage in short-term outcomes? A prospective comparative assessment in our center. Surg Endosc. 2013;27:2613-8.

26. Didziapetriene J, Kazbariene B, Surinenaite B, Krikstaponiene A, Ulys A, Uleckiene S, et al. Antioxidative system parameters and level of IL-18 after surgery in patients with renal cell carcinoma according to gender. Acta Physiol Hung. 2013;100:107-14. 
27. Fernandez-Real JM, Vayreda M, Richart C, Gutierrez C, Broch M, Vendrell J, et al. Circulating interleukin 6 levels, blood pressure, and insulin sensitivity in apparently healthy men and women. J Clin Endocrinol Metab. 2001;86:1154-9.

28. Ybarra J, Lehmann TNO, Golay A, Juge-Aubry CE, Roux-Lombard P, Dayer J, et al. Gender-based dimorphic pattern for interleukin-1 receptor antagonist in type 2 diabetes mellitus. Diabetes Metab. 2008;34:75-81.

29. Glatz T, Seifert G, Holzner PA, Chikhladze S, Kulemann B, Sick O, et al. A novel rodent model modifying perioperative temperature and humidity during bowel surgery and mimicking laparoscopic conditions. Surg Sci. 2012;3:353-7.

30. Glatz T, Boldt J, Timme S, Kulemann B, Seifert G, Holzner PA, et al. Impact of intraoperative temperature and humidity on healing of intestinal anastomoses. Int J Colorectal Dis. 2014;29:469-75.

31. Rosch R, Stumpf M, Junge K, Ardic D, Ulmer F, Schumpelick V. Impact of pressure and gas type on anastomotic wound healing in rats. Langenbecks Arch Surg. 2004;389:261-6.

32. Agalar F, Hamaloglu E, Daphan C, Tarim A, Onur R, Renda N, et al. Effects of $\mathrm{CO} 2$ insufflation and laparotomy on wound healing in mice. Aust N Z J Surg. 2000;70:739-42

33. Brokelman WJA, Lensvelt M, Borel Rinkes IHM, Klinkenbijl JHG, Reijnen MMPJ. Peritoneal changes due to laparoscopic surgery. Surg Endosc. 2011;25:1-9.

34. Yamamoto T, Umegae S, Kitagawa T, Matsumoto K. Intraperitoneal cytokine productions and their relationship to peritoneal sepsis and systemic inflammatory markers in patients with inflammatory bowel disease. Dis Colon Rectum. 2005;48:1005-15.

35. Fouda E, El Nakeeb A, Magdy A, Hammad EA, Othman G, Farid M. Early detection of anastomotic leakage after elective low anterior resection. J Gastrointest Surg. 2011;15:137-44.

\section{Submit your next manuscript to BioMed Central and take full advantage of:}

- Convenient online submission

- Thorough peer review

- No space constraints or color figure charges

- Immediate publication on acceptance

- Inclusion in PubMed, CAS, Scopus and Google Scholar

- Research which is freely available for redistribution 